\title{
전기자동차 $\mathrm{OBC}$ 용 $\mathrm{LLC}$ 공진형 컨버터의 설계절차
}

\author{
정용채" \\ Design Procedures of LLC Resonant Converter \\ for Electric Vehicle On-Board Charger
}

Yong-Chae Jung ${ }^{*}$

요 약

최근 양산되고 있는 하이브리드 전기자동차에 비해서 연비를 좀 더 개선하기 위한 플러그인 하이브리드 전 기자동차(Plug-in Hybrid Electric Vehicle)에 대한 연구가 활발히 진행되고 있다. 이 논문에서는 플러그인 하 이브리드 전기자동차를 위한 고효율의 탑재형 충전기(on-board charger)에 대해서 연구한다. 탑재형 충전기는 2상 인터리브드 PFC 회로와 LLC 공진형 컨버터로 구성된다. LLC 공진형 컨버터의 새로운 설계절차를 본 논 문에서 제안한다. 이는 매우 쉽고 강력한 방법이다. 위에서 언급한 내용을 확인하기 위해서 LLC 공진형 컨버 터를 설계하고 PSIM 툴을 이용하여 테스트한다.

\section{ABSTRACT}

nowadays, many researches for plug-in hybrid electric vehicles have been actively carried out to improve the gas mileage in comparison with mass-produced hybrid electric vehicles. In this paper, the on-board charger for plug-in hybrid electric vehicles is studied for obtaining the high efficiency. The on-board charger consists of two phase interleaved PFC circuit and LLC resonant converter. The new design procedures of LLC resonant converter are proposed in this paper. These are very simple and powerful method. In order to verify the abovementioned contents, the LLC resonant converter is designed and tested by using PSIM tool.

\section{키워드}

Electric Vehicle, PHEV, On-board charger, LLC, Resonant Converter 전기자동차, 플러그인 하이브리드 전기자동차, 탑재형 충전기, 엘엘씨, 공진형 컨버터

\section{I. 서 론}

다양한 분야에 $\mathrm{DC}-\mathrm{DC}$ 컨버터가 사용한다. 특히, $\mathrm{TV}$ 같은 분야에서는 최근 슬림한 제품이 유행이기 때문에 전원회로의 높이도 낮아야 하면서도 전원회로 의 손실도 매우 작아야 한다. 이러한 분야에 사용되는 회로가 LLC 공진형 컨버터이다. 이러한 특징 때문에 $\mathrm{LLC}$ 공진형 컨버터는 플러그인 하이브리드 전기자동 차(plug-in hybrid electric vehicle ; PHEV)의 탑재형 충전기(on-board charger)에도 사용되고 있다[1].

기존의 LLC 공진형 컨버터는 공진인덕터의 구조에 따라서 두 가지 방식으로 나뉜다[2-10]. 이러한 회로 를 설계하기 위한 기존 방식에는 Peak Gain의 곡선 이 필요했다. 하지만 이러한 곡선을 얻기 위해서는 복 잡한 계산과정이 필요하며 각 경우에 맞는 Peak Gain 곡선을 구해야 한다. 


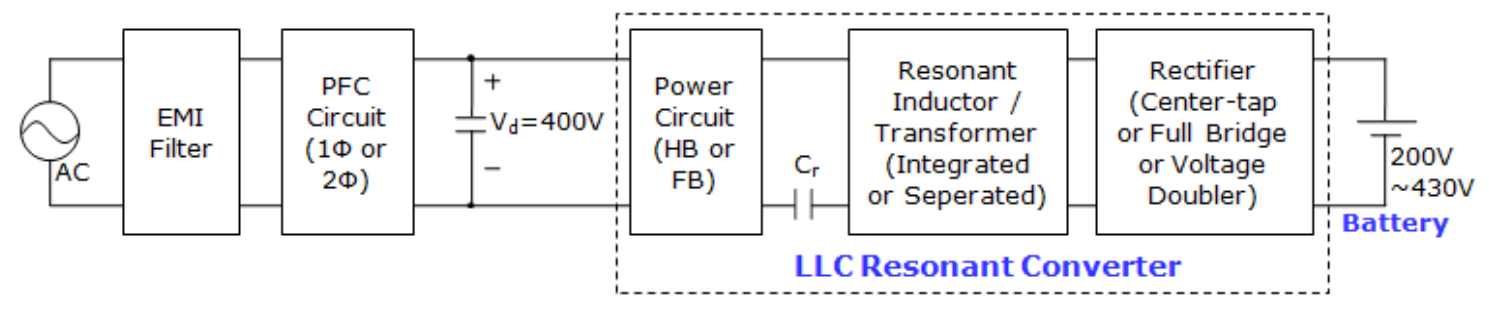

그림 1. 탑재형 충전기 회로의 구성

Fig. 1 Configuration of on-board charger

따라서 본 논문에서는 이러한 문제점을 해결하기 위해서 LLC 공진형 컨버터의 새로운 설계방법을 제 안한다. 제안된 방법에서는 좀 더 쉽게 공진소자들을 결정할 수 있기 때문에 좀 더 많은 분야에 LLC 공진 형 컨버터의 사용을 확대할 수 있을 것으로 판단된다. 2장에서는 LLC 공진형 컨버터에 대해서 설명하고 3 장에서는 새로운 설계방법을 제안한다. 4장에서는 $6.6 \mathrm{~kW}$ 출력을 위한 $7.2 \mathrm{~kW}$ 입력의 탑재형 충전기에 대해서 LLC 공진형 컨버터를 설계하고 PSIM 툴을 이용하여 설계된 회로의 동작을 확인한다.

\section{II. 탑재형 충전기용 LLC 공진형 컨버터}

그림 1 은 탑재형 충전기 회로의 구성을 보이고 있 다. 입력단에 역률제어회로가 사용되고 있어서 LLC 공진형 컨버터의 입력전압은 $400 \mathrm{~V}$ 이다. 이 역률제어 회로는 승압형 컨버터회로를 하나만 사용할 수도 있 고 두 개를 병렬로 사용할 수도 있다. 두 개를 병렬로 사용할 경우 입출력 리플전류를 줄이기 위해서 인터 리브 방식으로 제어를 한다.

LLC 공진형 컨버터는 회로방식에 따라서 여러 가 지 구성을 가질 수 있는데 먼저 power circuit을 보면 하프 브리지 컨버터 회로나 풀 브리지 컨버터 회로를 사용할 수 있다. 이 두 회로의 출력전압은 풀 브리지 회로가 하프 브리지 회로에 비해서 두 배 더 크다.

공진 인덕터와 트랜스포머는 일체형과 분리형으로 나뉜다. 일체형인 경우는 트랜스포머의 누설 인덕터가 공진 인덕터의 역할을 한다. 분리형인 경우는 트랜스 포머의 1,2 차측을 잘 결합시켜서 누설 인덕턴스가 최 소가 되도록 설계한다.
트랜스포머의 2차측에 연결된 정류부는 회로구성에 따라서 3 가지 회로방식을 사용한다. 센터텝 방식인 경 우는 트랜스포머의 2 차측 권선을 2 개로 하고 정류 다 이오드를 2 개만 사용한다. 반면에 풀 브리지 방식은 트랜스포머의 2 차측 권선을 1 개로 하고 정류 다이오 드를 4 개 사용한다. 배전압 방식은 풀브리지 방식에서 다이오드 2 개 대신에 커패시터를 2 개 사용하는 방식 이다.

이와 같이 LLC 공진형 컨버터를 설계하려면 총 12 가지의 회로를 모두 고려해야 한다. 기존의 방식들은 각 회로의 peak gain을 구해서 설계에 활용하고 있는 데 이 경우 12 가지의 peak gain 그래프가 필요하다. 이러한 그래프를 구할 수도 없고 그리기도 어렵기 때 문에 기존의 방식을 사용하여 회로 설계하기는 매우 어렵다.

\section{LLC 공진형 컨버터의 설계절차}

앞에서 언급한 문제점을 개선하기 위해서 본 논문 에서는 새로운 방식의 설계절차를 제안한다. 먼저 LLC 공진형 컨버터의 출력단 회로와 브리지 다이오 드 다음 단의 전류파형을 그림 2에서 함께 보여준다. 이 그림에서 전류파형은 공진주파수에서 동작할 때를 기준으로 그린 것이다. 따라서 브리지 다이오드 입력 단 전류는 사인파형이고 브리지 다이오드 출력단 전 류는 절대값을 취한 사인파형이다. 이 전류의 평균값 이 출력전류와 같기 때문에 사인파 전류의 피크값 $I_{p}$ 는 다음과 같이 계산할 수 있다. 


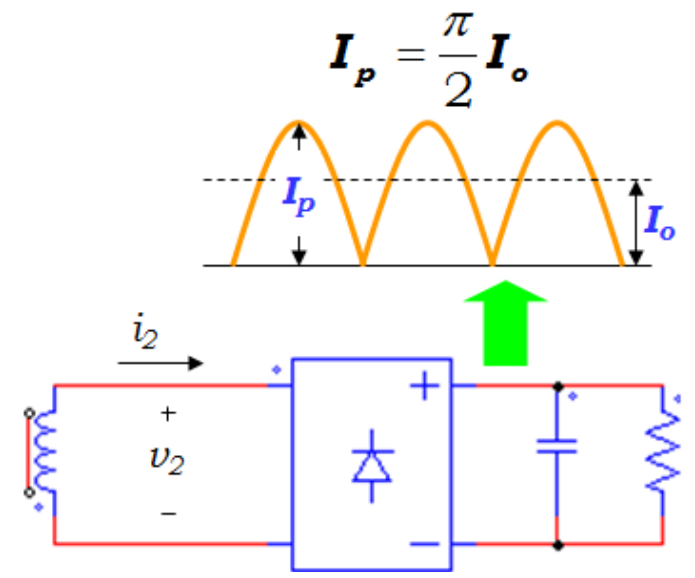

그림 2. LLC 공진형 컨버터의 출력 회로 Fig. 2 Output circuit of LLC resonant converter

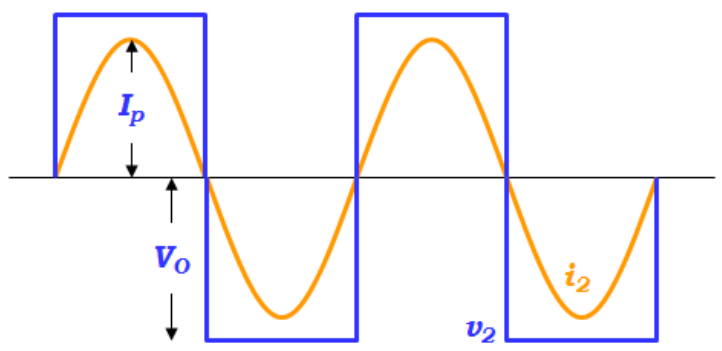

그림 3. 트랜스포머 2차측 전압 및 전류 파형

Fig. 3 Secondary voltage and current waveforms of transformer

$I_{p}=\frac{\pi}{2} I_{o}$

그림 3은 트랜스포머 2차측 전압과 전류를 보이고 있는데 양의 전류가 흐를 때 출력전압이 브리지 다이 오드 입력측에 보이고 음의 전류가 흐를 때 출력전압 이 브리지 다이오드 입력측에 뒤집어져 서 보여서 크 기가 $V_{o}$ 인 구형파로 보인다. 기본파 근사화법을 적용 하면 이 구형파는 이 구형파의 기본파 성분의 사인파 로 대치해도 같은 동작을 한다. 이 때 사인파 전압의 피크값 $V_{p}$ 는 다음과 같다.

$$
V_{p}=\frac{4}{\pi} V_{o}
$$

이와 같이 트랜스포머 2차측 전압과 전류는 동상의
사인파이므로 트랜스포머 2차측 회로를 다음과 같은 등가저항으로 대치할 수 있다.

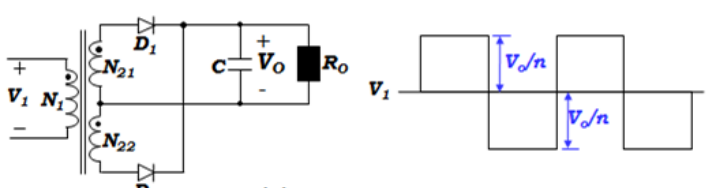

(a) center-tap type

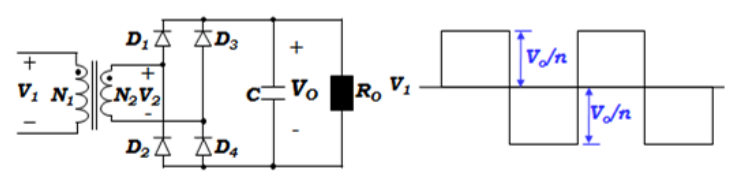

(b) full-bridge type

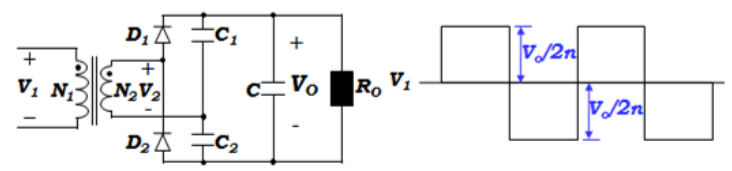

(c) voltage doubler type

그림 4. 정류부 방식에 따른 1 차측 전압파형

Fig. 4 Primary voltage waveforms according to rectifing methods

$R_{e q 2}=\frac{V_{p}}{I_{p}}=\frac{(4 / \pi) V_{o}}{(\pi / 2) I_{o}}=\frac{8}{\pi^{2}} R_{o}$

이 저항이 트랜스포머 1차측으로 넘어가면 다음 식 과 같이 턴 수 비의 제곱배해서 넘어간다.

$R_{e q}=n^{2} R_{e q 2}=n^{2} \frac{8}{\pi^{2}} R_{o}$

여기서 턴 수 비 noㅡㄴ 다음과 같이 정의되는 값이다.

$n=\frac{N_{1}}{N_{2}}=\frac{V_{1}}{V_{2}}=\frac{I_{2}}{I_{1}}$

또한 2 차측에 보이던 전압이 그림 4 와 같이 1 차측 으로 전달되어 보이는데 턴 수 비 $\mathrm{n}$ 으로 나눠진 값이 다. 2 차측의 회로방식에 따라서 전달되는 전압의 크기 가 달라지는데 배전압 방식이 다른 두 방식에 비해서 절반의 전압이 1 차측에 나타난다. 이는 턴 수 비가 절 반이기 때문이다.

1 차측에 보이는 전압이 자화 인덕터에 걸리는데 직 
류전압이기 때문에 자화인덕터의 전류는 그림 5 와 같 이 선형적으로 증가감소를 반복하는 삼각파 파형이 된다. LLC 공진형 컨버터의 1 차측 회로가 ZVS 특성 을 확보하려면 자화인덕터의 피크전류가 어느 정도 크기를 가져야 하는데 설계를 간편하게 하기 위해서 공진전류 피크치의 절반정도가 자화인덕터의 피크전 류가 되도록 기준을 정하였다.

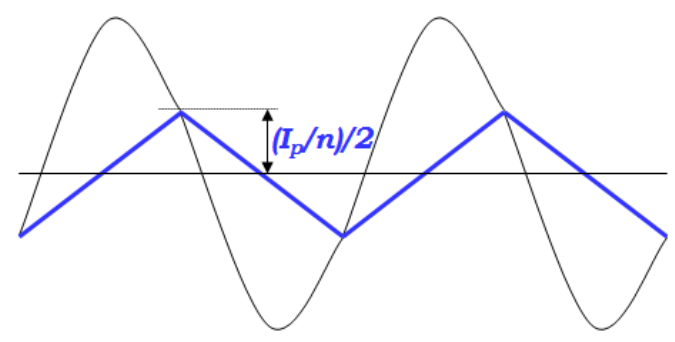

그림 5. 공진인덕터와 자화인덕터의 전류파형

Fig. 5 Current waveforms of resonant and magnetizing inductors

이 기준을 적용하여 자화인덕터를 식 (6)과 같이 계산할 수 있다.

$L_{m}=\frac{n^{2}\left(V_{o}+2 V_{F}\right)}{\pi I_{o} f_{r}}$

이 경우 트랜스포머의 이차측에 보이는 전압이 $V_{o}+2 V_{F}$ 인 경우이다. 다이오드가 하나만 도통하면 $V_{o}+V_{F}$ 를 사용하면 된다.

$L_{m}$ 이 정해지면 $L_{r}$ 과 $C_{r}$ 을 결정해야 하는데 $L_{p}$ 와 $L_{r}$ 의 비인 $\mathrm{m}=5$ 이고 공진주파수를 원하는 주파수로 미리 정해놓으면 각각 계산할 수 있다. 여기서 $L_{p}$ 는 $L_{m}+L_{r}$ 을 의미한다.

$L_{r}=L_{m} /(m-1)$

$C_{r}$ 은 공진주파수의 수식에서 역산으로 다음 식과 같이 계산할 수 있다.

$C_{r}=\frac{1}{L_{r} \omega_{r}^{2}}$

\section{IV. 시뮬레이션 결과}

앞 절에서 제안한 설계절차를 이용하여 설계된 내 용은 표 1과 같다. 이 설계된 결과값을 이용하여 PSIM 9.1을 이용하여 시뮬레이션을 진행하였다.

그림 6 은 출력전압이 $200 \mathrm{~V}$ 인 경우의 시뮬레이션 회로로 1차측 회로는 풀브리지 회로이고 2 차측 정류 회로도 풀브리지 방식을 취하고 있다. 1 차측의 각 스 위치에는 ZVS 특성을 얻기 위해서 병렬로 보조공진

표 1. 제안된 방식의 설계치

Table 1. Design values of the proposed method

\begin{tabular}{|c|c|c|}
\hline Items & Values & Remark \\
\hline Input voltage range & $390-410 \mathrm{~V}$ & PFC $\mathrm{V}_{\mathrm{o}}$ \\
\hline Min. output voltage & $200 \mathrm{~V}$ & \\
\hline Max. output voltage & $430 \mathrm{~V}$ & \\
\hline Output Power & $7,200 \mathrm{~W}$ & $\begin{array}{c}\text { Including } \\
\text { margin }\end{array}$ \\
\hline Resonant Freq. & $100 \mathrm{kHz}$ & \\
\hline Resonant inductor $\mathrm{L}_{\mathrm{r}}$ & $17 \mu \mathrm{H}$ & \\
\hline Magnetizing inductor $\mathrm{L}_{\mathrm{m}}$ & $68 \mu \mathrm{H}$ & \\
\hline Resonant capacitor $\mathrm{C}_{\mathrm{r}}$ & $150 \mathrm{nF}$ & \\
\hline Turn ratio $\mathrm{n}=\mathrm{N}_{\mathrm{p}} / \mathrm{N}_{\mathrm{s}}$ & 1.93 & \\
\hline
\end{tabular}
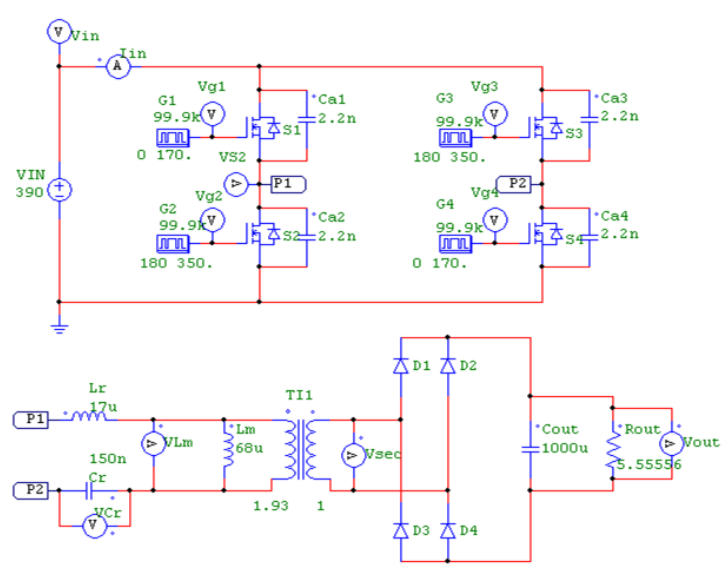

그림 6. $V_{0}=200 \mathrm{~V}$ 인 경우의 4 시뮬레이션 회로 Fig. 6 Simulation circuit in case of $V_{0}=200 \mathrm{~V}$ 
커패시터를 사용하였다. 그림 7 은 출력전력이 $7.2 \mathrm{~kW}$ 일 때의 시뮬레이션 파형인데 공진인덕터의 피크전류가 $32.75 \mathrm{~A}$ 이다. 그림 8은 출력전압이 $430 \mathrm{~V}$ 일 때의 시뮬레 이션 회로로 출력저항이 25.6805568인 경우이다. 그림 9 는 출력전력이 $7.2 \mathrm{~kW}$ 일 때의 시뮬레이션 파형인데 공 진인덕터의 피크전류가 $38.5 \mathrm{~A}$ 이다. 이 경우 스위칭주파 수가 $57.58 \mathrm{kHz}$ 로 주파수의 변동폭은 $42.42 \mathrm{kHz}$ 이다. 출 력이 $430 \mathrm{~V}$ 일 때는 이차측으로 전달되지 않는 자화인덕 터의 전류가 너무 커진다. 향후에 이 전류의 감소가 또 하나의 연구과제가 될 것이다.

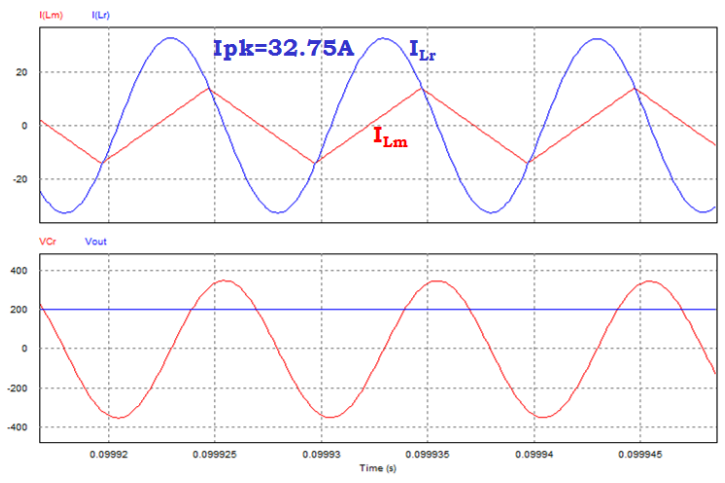

그림 7. $V_{0}=200 \mathrm{~V}$ 인 경우의 시뮬레이션 결과 Fig. 7 Simulation results in case of $V_{0}=200 \mathrm{~V}$

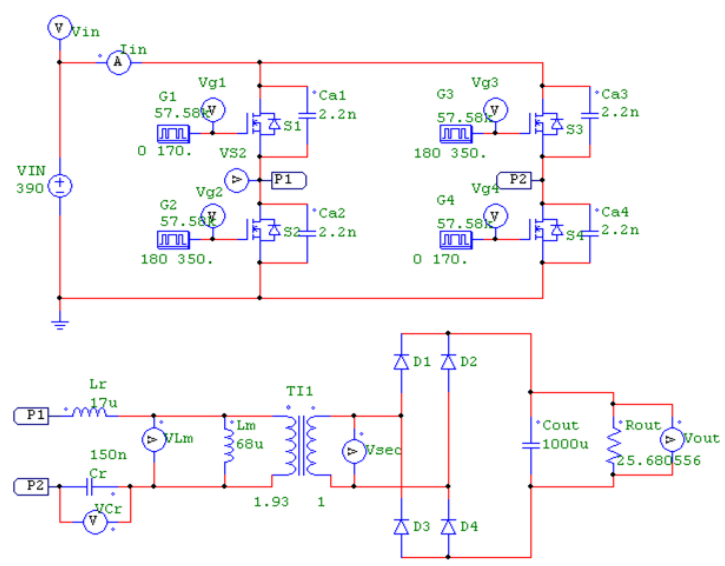

그림 8. $\mathrm{V}_{0}=430 \mathrm{~V}$ 인 경우의 시뮬레이션 회로 Fig. 8 Simulation circuit in case of $V_{0}=430 \mathrm{~V}$

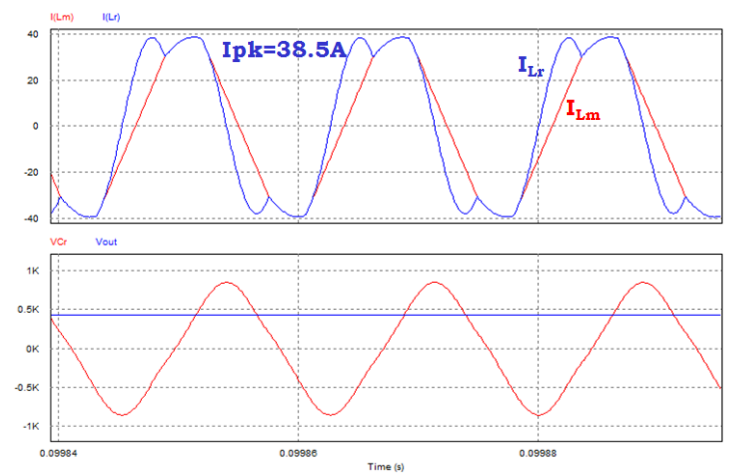

그림 9. $V_{0}=430 \mathrm{~V}$ 인 경우의 시뮬레이션 결과 Fig. 9 Simulation results in case of $V_{0}=430 \mathrm{~V}$

\section{V. 결 론}

본 논문에서는 전기자동차나 하이브리드 전기자동 차에 적용되는 탑재형 충전기에 사용되는 LLC 공진 형 컨버터의 새로운 설계절차를 제안하였다. 기존의 방법은 Peak Gain에 대한 정보가 있어야 설계가 가 능했지만 새롭게 제안된 설계방법은 상당히 간단한 기준을 사용하여 공진소자들을 설계하였다. 제안된 방 식의 유용성을 확인하기 위해서 PSIM 툴을 이용하여 시뮬레이션을 진행하였고 제안된 방식이 타당하다는 것을 확인하였다.

\section{감사의 글}

이 논문은 2013년 남서울대학교 교내 연구비 지원에 의하여 연구되었음

\section{참고 문헌}

[1] D. Gautam, F. Musavi, M. Edington, W. Eberle and W. G. Dunford, "An Automotive On-Board 3.3kW Battery Charger for PHEV Application," IEEE VPPC, 2011, pp. 1-6.

[2] H.-S. Choi, "Design Consideration of HalfBridge LLC Resonant Converter," J. of Power Electronics, vol. 7, no. 1, pp. 13-20, January 2007. 
[3] J.-H. Jung, J.-M. Choi, and J.-G. Kwon, "Design Methodology for Transformers Including Integrated and Center-tapped Structures for LLC Resonant Converters," J. of Power Electronics, vol. 9, no. 2, Mar. 2009, pp. 215-223.

[4] H.-S. Choi, "Half-bridge LLC Resonant Converter Design Using FSFR-series Fairchild Power Switch (FPS $\left.{ }^{\mathrm{TM}}\right), "$ Fairchild Semiconductor Application Note, AN-4152, Oct. 2007.

[5] Y. Liu, "High Efficiency Optimization of LLC Resonant Converter for Wide Load Range," Master Thesis of Virginia Polytechnic Institute and State University, Dec. 2007.

[6] Y.-S. Ko, "The Development of Collection Solution of the Three-Phase Power Data based on the Personal Computer for Supporting the Smart Grid," J. of the Korea Institute of Electronic Communication Sciences, vol. 6, no. 4, 2011, pp. 553-558.

[7] Y.-C. Jung, “Input Ripple Current Formula Analysis of Multi-Stage Interleaved Boost Converter," J. of the Korea Institute of Electronic Communication Sciences, vol. 6, no. 6, 2011, pp. 865-872.

[8] Y.-C. Jung, “A Study on Generalized Output Capacitor Ripple Current Equation of Interleaved Boost Converter," J. of the Korea Institute of Electronic Communication Sciences, vol. 7, no. 6, 2012, pp. 1429-1435.

[9] Y.-C. Bae, "A Behavior Analysis in the Circular Hybrid Subminiture Energy Harvesting Device," J. of the Korea Institute of Electronic Communication Sciences, vol. 8, no. 11, 2013, pp. 1691-1696.

[10] S.-I. Park and J.-G Lee, “Design of Smart Off-Board Charge System for Neighborhood Electric Vehicle," J. of the Korea Institute of Electronic Communication Sciences, vol. 8, no. 10, 2013, pp. 1499-1504.
저자 소개

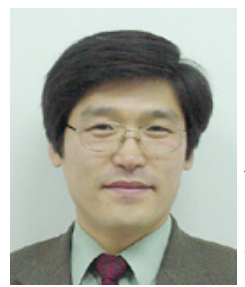

\section{정용채(Yong-Chae Jung)}

1989년 2월 한양대학교 전자공학 과(공학사) 1991년 2월 한국과학기술원 전기 및 전자공학과(공학석사) 1995년 8월 한국과학기술원 전기 및 전자공학과 (공학박사)

1991년 8월 1999년 6월 : LG전자 홈어플라이언스 연구소 선임연구원

1999년 현재 남서울대학교 전자공학과 교수 ※ 관심분야 : 전력전자, DC-DC 컨버터, 태양광 발 전, 전기자동차, $\mathrm{PFC}$ 회로, $\mathrm{EMI}$, 유도가열 